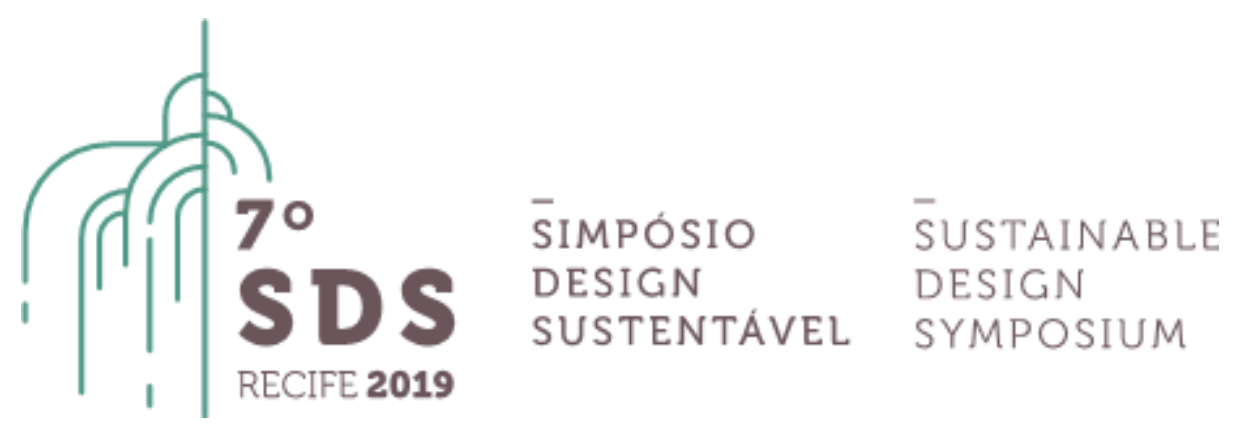

\title{
Design da Terra: Produção de objetos a partir da indução de plantas.
}

\author{
Alice Pantoja Damasceno ${ }^{1}$, Antonio Erlindo Braga Jr. ${ }^{2}$, Gabriela Rodrigues Pessoa ${ }^{3}$ e Jamille Santos dos Santos ${ }^{4}$ \\ ${ }^{1}$ Universidade do Estado do Pará, Bacharelanda em Design, damasceno.alice23@gmail.com \\ 2 Universidade do Estado do Pará, Doutor em Engenharia de Produção, erlindo@uepa.br \\ 3 Universidade do Estado do Pará, Bacharelanda em Design, gabrielapessoa10@gmail.com \\ ${ }^{4}$ Universidade do Estado do Pará, Bacharelanda em Design, jamille.s2000@gmail.com
}

\begin{abstract}
Resumo. O presente artigo busca documentar e apresentar o início da aplicação do projeto "Design da Terra" demonstrando suas metodologias, técnicas e expectativas para o futuro. O Design da Terra é um projeto que inclui os conceitos do Biodesign (em contrapartida ao modelo ortodoxo de produção) na criação de artefatos a partir da indução de galhos de plantas por meio de moldes. Desse modo, é possivel discutir questões relacionadas à sustentabilidade diretamente, pois desta maneira é possível produzir sem invalidar o cultivo e outras práticas agrícolas que prejudicam o meio ambiente, diminuindo assim o desperdício de matéria prima. Além disso, o projeto tem sido pensado para comunidades rurais da região amazônica, na busca por contribuir na revalorização cultural e fomento da economia local. Para viabilizar isso, a ideia é criar um Sistema Produto-Serviço que possibilite o compartilhamento de máquinas e ferramentas para o acabamento dos artefatos plantados nas comunidades.
\end{abstract}

Palavras-chave. Amazônia, Artefatos, Biodesign, Sistema Produto-Serviço. Sustentabilidade, Revalorização.

\section{Introdução}

Nos últimos anos, é possível perceber as mudanças ambientais que o planeta enfrenta, causadas pela imprudência humana. A poluição de rios, lagos e oceanos, as desigualdades sociais e a escassez dos recursos em contrapartida ao consumo desenfreado tornaram-se preocupações imediatas. Por esta razão foram realizadas diversas conferências ambientais que culminaram no surgimento de novas leis, ações e projetos no mundo inteiro, na busca pelo desenvolvimento 
sustentável, a fim de preservar o planeta em que vivemos. Em meio a isso, o projeto "Design da Terra" surge com o objetivo de contribuir para a sustentabilidade e a revalorização cultural no contexto da região amazônica em união às comunidades do estado do Pará.

O conceito de sustentabilidade tem sido aplicado em cada vez mais projetos de diversas áreas do conhecimento. Foi dividido em três pilares, descritos por Oliveira, et al (2012):

\begin{abstract}
Analisando-os separadamente, tem-se: Econômico, cujo propósito é a criação de empreendimentos viáveis, atraentes para os investidores; Ambiental, cujo objetivo é analisar a interação de processos com o meio ambiente sem the causar danos permanentes; e Social, que se preocupa com o estabelecimento de ações justas para trabalhadores, parceiros e sociedade. Juntos, no entanto, estes três pilares se relacionam de tal forma que a interseção entre dois pilares resulta em viável, justo e vivível, e dos três, resultaria no alcance da sustentabilidade.
\end{abstract}

Segundo Manzini e Vezzoli (2002), a Sustentabilidade Ambiental pode ser entendida como a forma correta da abordagem na qual o ser humano pode utilizar os recursos naturais, levando em consideração as questões ambientais relacionadas à capacidade que o planeta possui de preservar os seres vivos sem ultrapassar os seus limites de resiliência ou interferir nos ciclos naturais, prezando pela conservação desses recursos para que as gerações subsequentes também possam usufruir. A partir disso, é possível entender que o modelo de produção desenvolvimentista atual deve buscar formas alternativas de manufatura para que o conceito de sustentabilidade ambiental possa ser exercido da melhor forma. Sob essa perspectiva, o projeto "Design da Terra" almeja o alcance da produção de objetos a partir da indução de plantas adaptadas às condições regionais fomentando a minimização de resíduos, aplicação do sistema produto-serviço nas máquinas de refinamento do produto, estímulo ao consumo consciente e respeito ao tempo da natureza.

Assim sendo, os autores optaram por aplicar também os conceitos de Design e Território no projeto, pois estes buscam abordar não só os fatores ambientais, como também as vertentes econômicas e sociais, a fim de atender os requisitos de sustentabilidade e melhorar a sua aplicação. Segundo Krucken (2009) o Design busca implementar estratégias que tornem os processos e soluções mais sustentáveis, reduzindo os danos ao meio ambiente e proporcionando uma melhor qualidade de vida às pessoas. É responsabilidade do designer comunicar tais valores socioambientais ao consumidor de forma clara e objetiva através do produto.

Pretende-se levar em conta todas características da região a qual o projeto será executado, visando abranger as especificidades locais para atendê-las de forma conjunta, inter-relacionando produtores e empresas a fim de potencializar as habilidades de ambos e integrá-las de forma homogênea. Nesse sentido, são gerados benefícios para os produtores locais e para o próprio designer, tendo em vista a troca de conhecimento. A atuação do designer no território será em parceria com a população local, considerando os saberes e técnicas que já se fazem ali presentes. Portanto, ao invés de se apropriar de uma matéria-prima ou cultura, o trabalho será realizado de maneira integrada, visando buscar inspirações e agregando valor ao trabalho de um grupo.

O projeto está sendo fundamentado em pesquisas similares para adaptar o conhecimento atual às condições locais para, posteriormente, dar início ao repasse junto às comunidades de pequenos produtores, como mostra a figura 1.

Figura 1 - Cronologia de aplicação do projeto. 


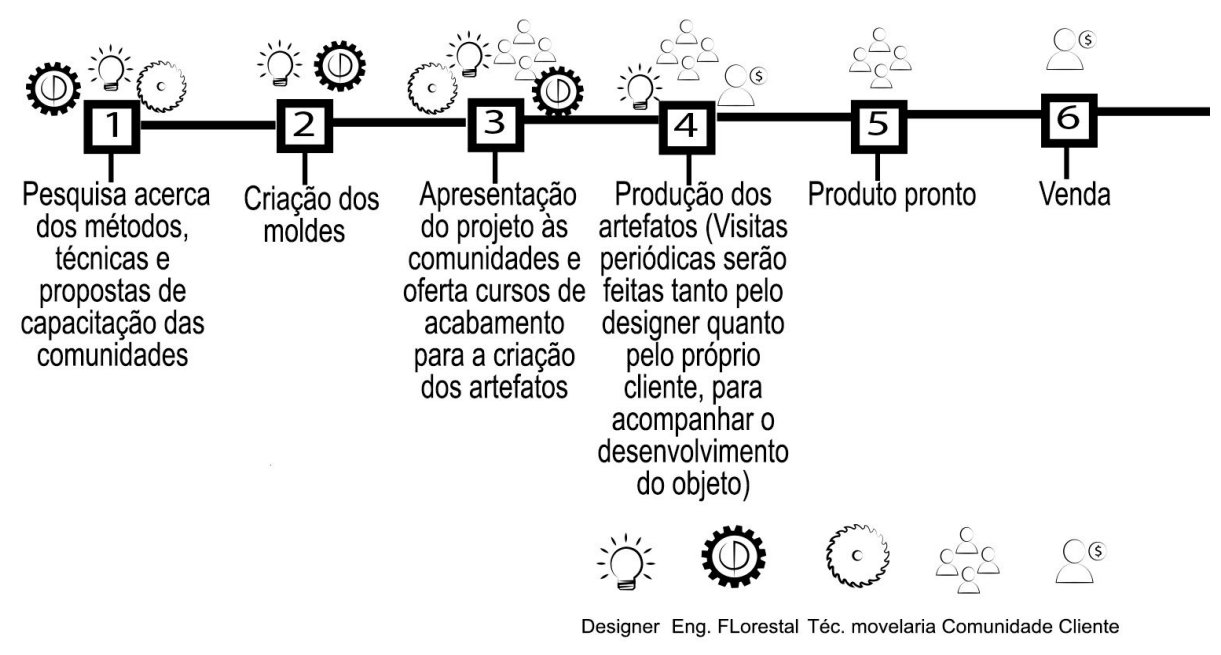

Fonte: Autores, 2019.

\section{O Biodesign Aplicado ao Projeto de Produtos}

O projeto surgiu a partir de reuniões do grupo de estudo LeNS (Learning Network on Sustainability) na sede da região de Belém - promovido pela Universidade do Estado do Pará e coordenado por membros do Curso de Bacharelado em Design. Este desenvolve pesquisa e extensão universitária buscando uma nova forma de produção que minimize os impactos ambientais e proporcione a revalorização cultural das comunidades rurais ao qual se deseja cocriar, tendo em vista que estas possuem fortes demandas financeiras e sociais.

A iniciativa busca uma revalorização da produção por meio da aplicação do "Design da Terra" no estado do Pará com o intuito de expandi-la para outros espaços no território nacional. Entende-se que é possível agregar valor e trazer visibilidade para as comunidades, utilizando a metodologia da indução do crescimento guiado dos galhos, com moldes no formato desejado, criando assim, novos produtos.

Para isto compreende-se que os produtos gerados são cocriados com a própria natureza, desviando da visão ortodoxa de produção. Por conta disso, o trabalho permite a parceria entre organismos vivos e a própria atuação do designer, onde cada um desempenha um papel específico na criação do produto e o tempo biológico das espécies escolhidas é respeitado. Nesta perspectiva, Myers (2018) afirma que projetos que exercem o se diferem da biomimética por dissolver as fronteiras entre o natural e o construído, incorporando estruturas vivas como componentes essenciais no trabalho acabado, construindo novas tipologias híbridas.

Uma das referências utilizadas para embasar o projeto é o trabalho do designer Gavin Munro, fundador da empresa Full Grown. Este consiste na criação de moldes para a orientação do crescimento das plantas e acabamento para o desenvolvimento de cadeiras e luminárias sob encomenda. Segundo Munro (2019), o objetivo é a atuação conjunta de artesão e natureza onde a árvore cresce em seu próprio rumo e estilo e o designer apenas a orienta de tempos em tempos para garantir que siga o curso do desenho que caracteriza o produto pretendido (o formato de uma cadeira de quatro pernas, por exemplo), assim deixando-a livre para crescer no sentido que deseja e confeccionando peças únicas.

Figura 2 - Plantas moldadas. 


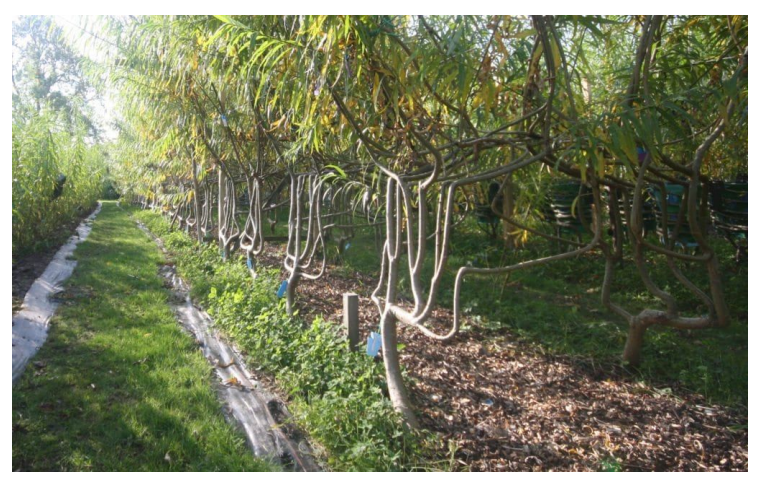

Fonte: Munro, 2017.

Além do Full Grown, outra referência utilizada para fundamentar o "Design da Terra" foi o Baubotanik, técnica criada pelo arquiteto Ferdinand Ludwig (ARCHDAILY, 2019) que compreende a criação de projetos arquitetônicos integrando árvores, andaimes de metal e outros materiais de construção através do processo de enxertia. Este processo consiste na união de duas árvores - da mesma espécie ou de espécies diferentes - fazendo o tecido interno destas entrarem em contato, assim permitindo a mesclagem de suas seivas e produzindo uma união que se fortalece gradualmente conforme o tempo passa. Esse método, aliado à inserção de metais e plásticos na fase inicial do crescimento da árvore permite a cocriação de edifícios em parceria com a natureza, onde, acima de tudo, deve ser respeitada as regras botânicas de crescimento. Tal pensamento entra em consenso com o posicionamento do idealizador do Full Grown e será levado em consideração durante a execução do projeto.

\section{O Sistema Produto-Serviço}

No que tange o processo de finalização dos artefatos após o corte, há a necessidade de máquinas de acabamento das superfícies para polimento do produto. A partir dessa necessidade, o grupo desenvolve pesquisas sobre Sistema Produto-Serviço a fim de promover a interação entre as comunidades envolvidas no projeto. Pois a partir da compreensão de que a utilização dessas máquinas é periódica, o uso destas estaria disponível de acordo com a necessidade da utilização de cada comunidade, havendo um rodízio das máquinas e equipamentos.

O Sistema Produto-Serviço (Product Service-System, PSS) é definido como um sistema que une serviços e produtos visando o cumprimento da demanda do cliente, com base em interações inovadoras entre stakeholders, em que a busca contínua de novas soluções benéficas tanto ambientalmente quanto socialmente é fomentada pelo interesse econômico e competitivo dos fornecedores (VEZZOLI ET AL, 2018). Este é dividido em três categorias: orientado ao produto, orientado ao uso e orientado ao resultado. Para a concepção deste projeto, o PSS orientado ao uso é o mais adequado, tendo em vista que neste sistema os produtos (na maioria dos casos), são de propriedade do provedor do serviço, que deve garantir a manutenção, reparo e controle do produto (TUKKER, 2004). A partir disso, tendo em vista que o crescimento das plantas se dá de diferentes formas e períodos em cada lugar, seria viável a utilização das mesmas máquinas por diversos produtores em diferentes ciclos. Dessa forma, todos poderão usufruir de um serviço de qualidade fornecendo maquinário com boa manutenção, além de diminuir o consumo.

\section{Metodologia}

A metodologia utilizada é o estudo de caso relacionando a abordagem junto à comunidade e a interação com o usuário. Compreende-se que é essencial que o projetista esteja em contato direto com seu público alvo, observando suas necessidades e dificuldades para que possa atendê-las da melhor forma, sem negligenciar aspectos que só podem ser percebidos pelo próprio 
usuário (MASTEN; PLOWMAN, 2003). Além disso, atividades de imersão na comunidade são indispensáveis na implantação, pois é necessário pensar nas necessidades de todas as pessoas envolvidas, não só no uso, como também em toda a cadeia de produção.

Apesar dos diversos fatores citados no projeto, acerca das vantagens em implantá-lo, é evidente a necessidade de um público para consumir os produtos, e buscando conquistar esse grupo de consumidores, o "Design da Terra" pretende não só fornecer o produto físico, mas a se desenvolver com base no UX Design (experiência do usuário), uma vertente do Design que busca melhorias entre a interação humano-objeto, além de conceitos de diversas áreas de atuação, como por exemplo a psicologia, que permitem melhorar essa interação buscando fornecer um serviço eficaz, gerar uma experiência cada vez melhor para o cliente, e assim aprimorar a usabilidade do produto.

Para melhor entendimento de como funciona o UX Design, é necessário observar que quando fazemos uso de qualquer objeto, existe uma relação de experiência entre o usuário e o produto, podendo esta ser positiva ou negativa. O papel do Designer nesse sentido, consiste em analisar as mais diversas experiências, buscando em outras áreas do conhecimento, entender os pontos comuns que agradam o consumidor, além de realizar pesquisas etnográficas e observações. Assim, é possível tornar a experiência do usuário cada vez melhor (TEIXEIRA, 2014).

\section{1 - Técnicas}

A realização da produção dos moldes ocorrerá de modo similar ao Full Grown (figura 3), estudando o que é mais viável ao clima da região amazônica e adaptação das espécies de plantas.

Figura 3 - Plantas com os moldes.

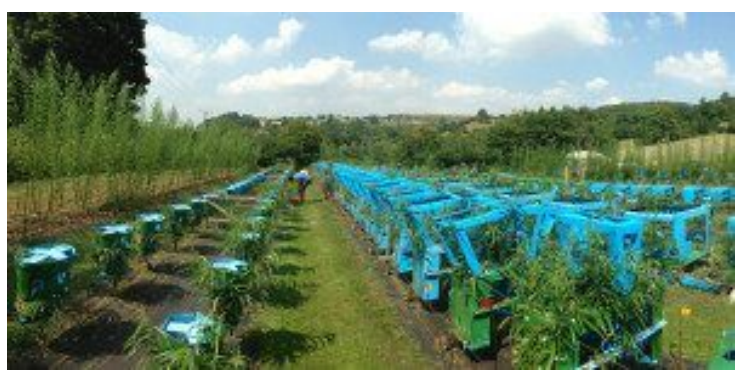

Fonte: Munro, 2017.

Ademais para a união de características desejáveis da planta que possibilitem o resultado esperado tanto durante a produção, quanto para o produto finalizado, a enxertia será um importante auxílio, pois a partir desta será possível adicionar galhos (onde não há) em ângulos mais acentuados, possibilitando novas ramificações que darão forma aos objetos produzidos.

Esta técnica consiste na introdução de uma planta (porta-enxerto) em outra (enxerto) através da regeneração de tecidos que se unem e continuam seu crescimento como um ser único (CAVALCANTI JUNIOR, 2013), como apresentado na figura 4.

Figura 4 - Série de cortes do processo de enxertia. 


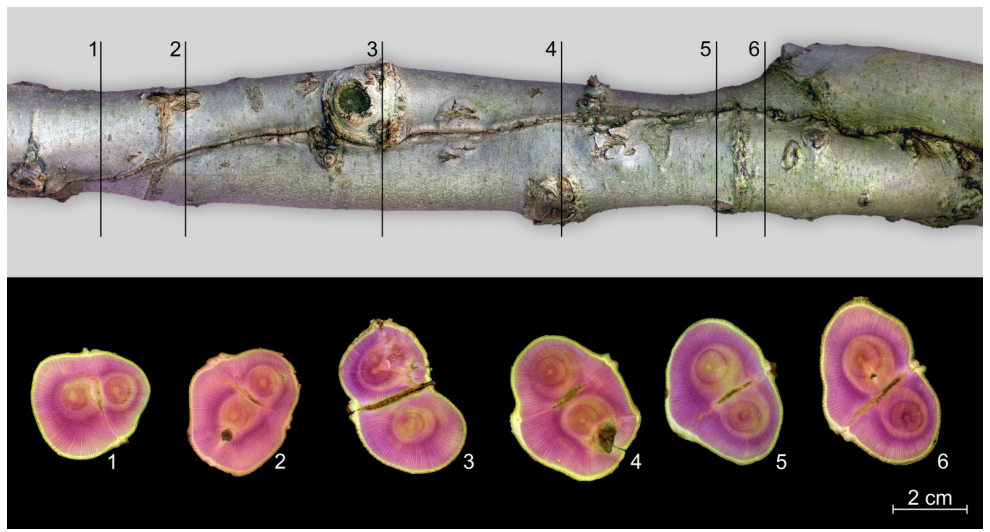

Fonte: ArchDaily, 2019.

\section{Aplicação}

Para os primeiros testes de aplicação do projeto, foram adquiridas mudas de algumas espécies, sendo elas: Marupá (10 mudas), Paricá (10 mudas), Teca (11 mudas) e Sansão do Campo (10 mudas), figuras 5, 6, 7 e 8, respectivamente. Estas foram escolhidas de acordo com pesquisas acerca da compatibilidade das plantas com o propósito do projeto e estão em fase de avaliação.

Figura 5 - Marupá.

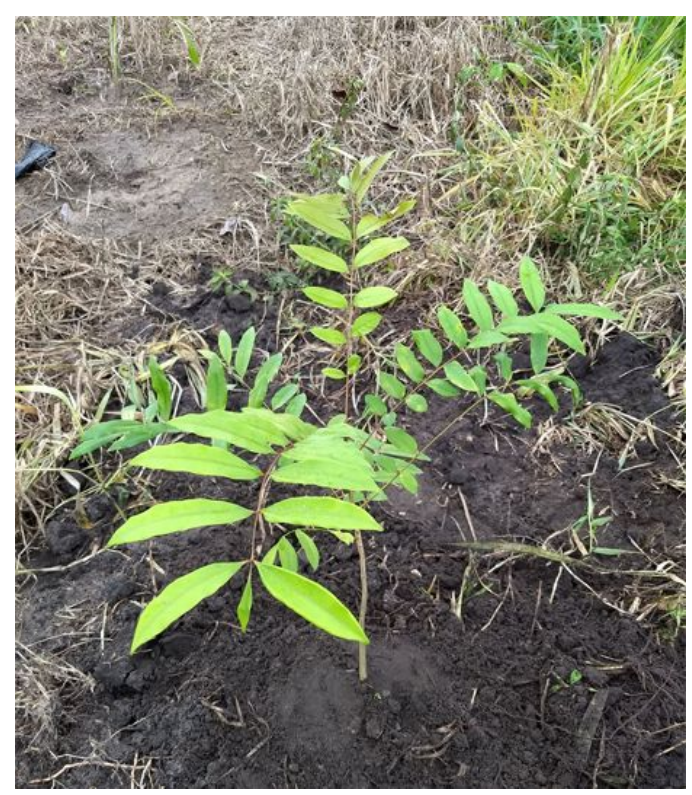

Fonte: Autores, 2019.

Figura 6 - Paricá. 


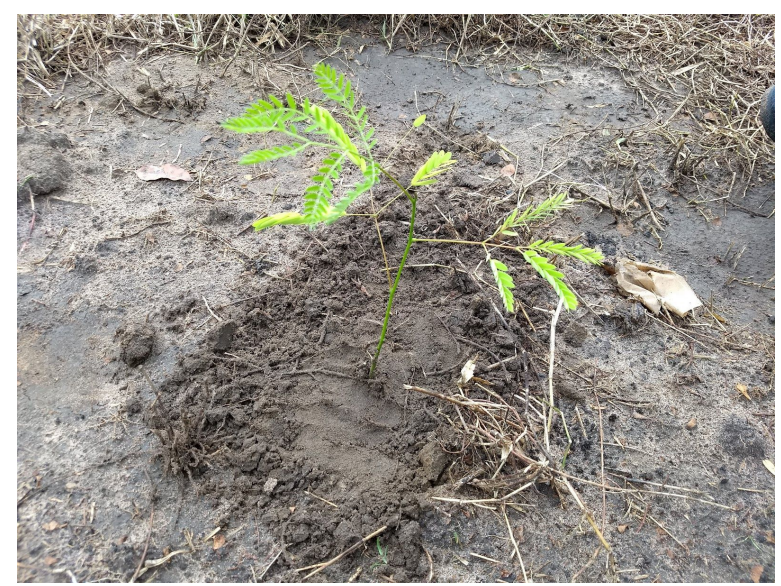

Fonte: Autores, 2019.

Figura 7 - Teca.

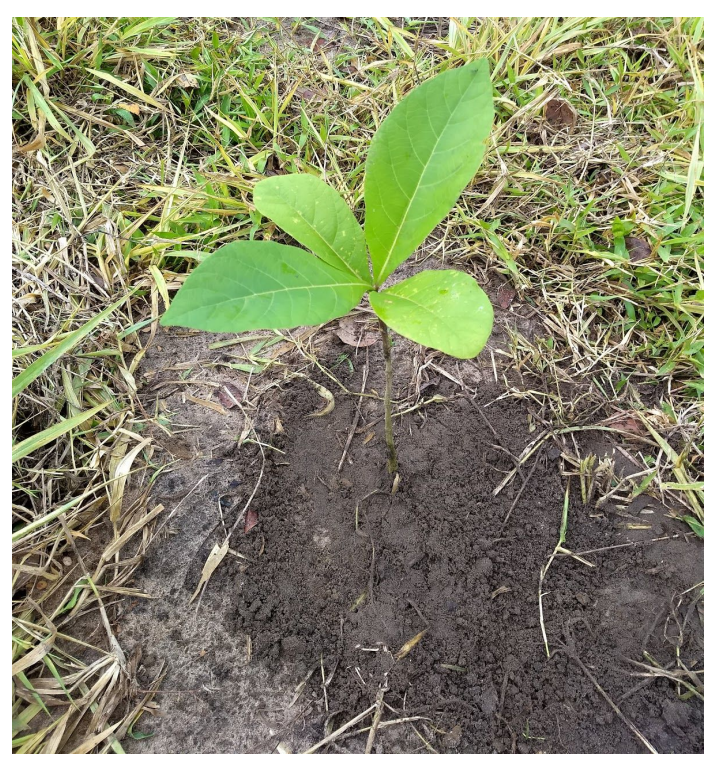

Fonte: Autores, 2019.

Figura 8 - Sansão do Campo.

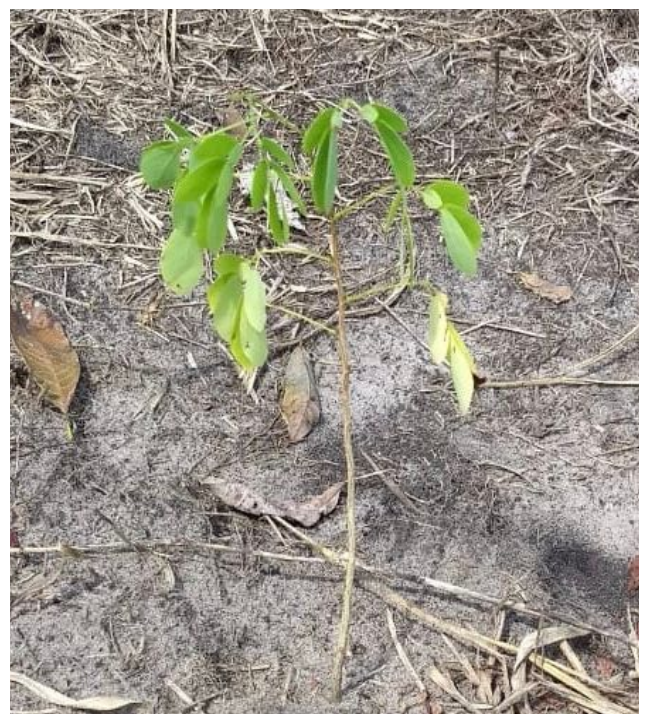


Estas espécies foram selecionadas por possuírem as seguintes características: boa geração de ramos, flexibilidade nos ramos, rápido crescimento, boa resistência mecânica,boa aceitação ao processo de enxertia e boa adaptação ao clima da região. Mensalmente estão sendo realizadas visitas para coleta de dados dendométricos. Ademais, os moldes serão produzidos de acordo com o que está sendo observado no crescimento das plantas. Por isso, o grupo tem desenvolvido esboços (figura 9) que priorizam as formas orgânicas das plantas para produzir os moldes a partir destes.

Figura 9 - Esboços do formato dos artefatos.

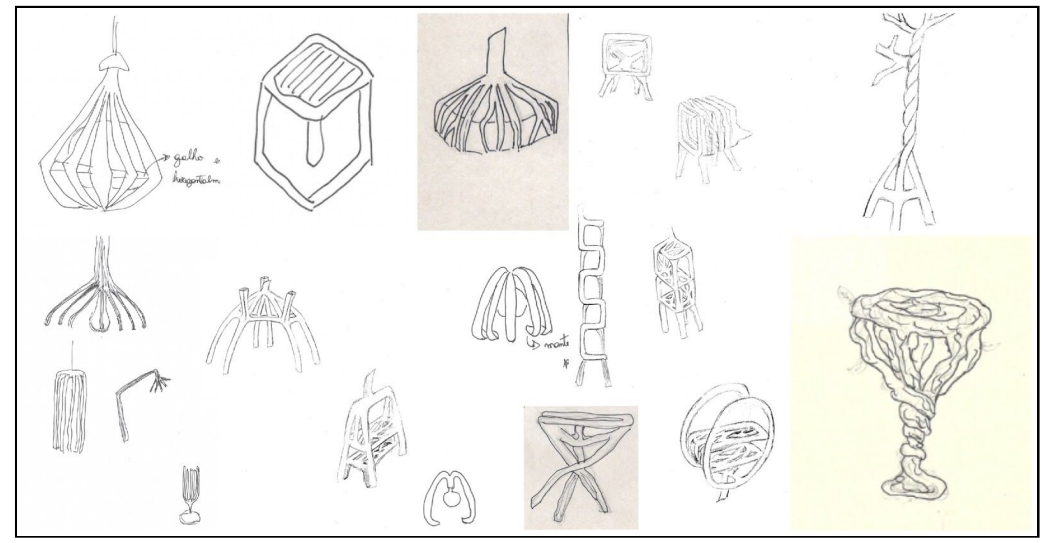

Fonte: Autores, 2019.

Serão criados 5 moldes, divididos entre 3 luminárias, 1 banco e 1 mesa. Estes serão submetidos às mudas 6 meses após o plantio e permitirão a avaliação da viabilidade das espécies para a produção.

\section{Expectativas para o futuro}

No ano de 2019, o grupo de pesquisa pretende analisar a adaptação das mudas já adquiridas a todas as demandas do projeto e produzir os moldes para dar início à prototipação destes.

O projeto busca atuar como facilitador da produção, repassando as técnicas apresentadas e as aliando aos conhecimentos da população das comunidades do estado do Pará, no intuito de fomentar a economia local, utilizando processos e produtos sustentáveis

Após isso, planeja-se iniciar a implantação em comunidades rurais localizadas nas ilhas próximas à capital do estado, e a implantação será em conjunto com os agricultores e artesãos da região, unindo a pesquisa aos conhecimentos empíricos relacionados ao clima, ao crescimento das árvores e às formas de cultivo. Tendo em vista que o projeto tem caminhado para a prototipação, as técnicas e conceitos aqui expostos têm funcionado como material de pesquisa para adaptação ao contexto ao qual o projeto está inserido, respeitando os limites de resiliência e buscando equidade social no que tange ao espaço ambiental.

\section{Referências}

ARCHDAILY. Baubotanik: um sistema construtivo inspirado na botânica que cria estruturas vivas. Disponível em: <https://bit.ly/2kyg324>. Acesso em: 24 de abril de 2019.

CAVALCANTI JÚNIOR, Antonio Teixeira. Propagação assexuada do cajueiro. Brasília, DF: Embrapa, 2013. 
KRUCKEN, Lia. Design e Território: valorização de identidades e produtos locais. São Paulo: Studio Nobel, 2009.

MANZINI, Ezio; VEZZOLI, Carlo. O desenvolvimento de produtos sustentáveis: Os requisitos ambientais dos produtos industriais. 1. SP: Edusp, 2002.

MASTEN, Davis; PLOWMAN, Tim M. P. Digital ethnography: the next wave in understanding the consumer experience. Design Management Journal, [S. I.], v. 14, n. 2, 2003.

MUNRO, Gavin. Full Grown. Disponível em: < https://fullgrown.co.uk/>. Acesso em: 24 de abril de 2019.

MYERS, William. BIODESIGN : Nature + Science + Creativity. Nova lorque: Museum of Modern Art (MoMA) in New York and Thames \& Hudson, 2018.

OLIVEIRA, L. R. D. et al. Sustentabilidade: da evolução dos conceitos à implementação como estratégia nas organizações. Production Journal, RJ, v. 22, n. 1, p. 70-82, jan./fev. 2012.

TEIXEIRA, Fabrício. Introdução e boas práticas do ux design. SP: Casa do Código, 2014.

TUKKER, A. Eight types of product-service system: eight ways to sustainability? Experiences from Suspronet. Business Strategy and the Environment. V.13, p. 246- 260, 2004.

VEZZOLI, Carlo et al. Sistema produto + serviço sustentável : fundamentos. Curitiba: Editora Insight. 2018. 